\title{
Characterization of acid soluble collagen (ASC) and pepsin soluble collagen (PSC) extracted from shortfin scad (Decapterus macrosoma) waste
}

\author{
Sulaiman, A.W. and *Sarbon, N.M. \\ Faculty of Fisheries and Food Science, Universiti Malaysia Terengganu, Kuala Terenggan Nerus, 21030, \\ Terengganu, Malaysia
}

\author{
Article history: \\ Received: 5 June 2020 \\ Received in revised form: 15 \\ July 2020 \\ Accepted: 29 July 2020 \\ Available Online: 22 \\ September 2020

\section{Keywords:} \\ Collagen, \\ Acid soluble collagen (ASC), \\ Pepsin soluble collagen \\ (PSC), \\ Extraction method, \\ Shortfin scad (Decapterus \\ macrosoma)
}

\section{DOI:}

https://doi.org/10.26656/fr.2017.4(6).267

\begin{abstract}
Fish waste management is one of the biggest impacts towards the environment. However, it is one of the rich sources of protein. Therefore, the aim of this study was to isolate and characterize acid soluble collagen (ASC) and pepsin soluble collagen (PSC) from shortfin scad (Decapterus macrosoma) waste, with the yields of ASC $(3.35 \pm 3.43 \%)$ and PSC $(0.10 \pm 0.13 \%)$ respectively. The isolated ASC and PSC from shortfin scad waste were characterized on chemical composition, protein concentration, structural properties by FTIR, solubility and morphology properties compared to the commercial collagen from tilapia (Oreochromis niloticus) scales. In terms of chemical composition, PSC showed better than ASC, since it contains comparatively higher in protein $(26.97 \pm 1.02 \%)$ by Kjeldahl method and protein concentration $(2.69 \pm 0.47 \mathrm{mg} / \mathrm{mL})$ by biuret method, compared to ASC. The FTIR investigations also certified the existence of spacial triplehelical structures of collagens that are important for collagen backbones. Solubility results showed that both ASC and PSC are high insolubility at acidic $\mathrm{pH}$ with the lowest solubilisation point at the range of alkali condition. The morphological analysis of both ASC and PSC were almost similar too, as there were fibrils and porous structure. Therefore, collagen from shortfin scad waste, could be a useful alternative, with the potential to be used in food ingredient, biomedical, pharmaceutical and nutraceuticals industries.
\end{abstract}

\section{Introduction}

Collagen is the most abundant extracellular matrix found in animals, accounting for $30 \%$ of the total protein in the animal body (Hukmi and Sarbon, 2018; Baderi and Sarbon, 2019). Collagen is characterized by domains with repetitions of proline-rich tripeptides, in the form of glycine, proline and hydroxyproline or hyroxylysine that are important in flexibility properties (Bond, 2014; Hamdan and Sarbon, 2019; Baderi and Sarbon, 2019). Aquatic animals recognised as potential resources for the new source of collagen, due to dietary restriction and lack of disease transmission (Liu et al., 2010; Hamdan and Sarbon, 2019). There are about twenty-eight different types of collagen have been identified as type I - XXVII, that composed of at least 46 distinct polypeptide chains in vertebrates, and many other proteins that contain collagenous domains (Veit et al., 2006). However, type I collagen is the fibrous collagen and found as the major type in fish waste materials including skin, bone, scale and fins of various fish species (Mahboob, 2015; Baderi and Sarbon, 2019). This collagen type I is usually used in food industries, cosmetic, pharmaceutical, biomedical, and tissue engineering due to its excellent biocompatibility and biodegradability (Liu et al., 2010).

The preparation of collagen protein includes a selection of the materials, pre-process, extraction, separation, purification and many others. In extraction process of collagen, there are about four types of methods, which are acid extraction, enzyme extraction, alkaline extraction and salting out extraction (Yang and Shu, 2014; Baderi and Sarbon, 2019). In the salting out method, sodium chloride, tris-hydrochloric acid, phosphate and citrate are used. While in the alkali method, lime, sodium hydroxide, sodium carbonate and magnesium oxide is used. Meanwhile, in enzymatic extraction, enzymes used are pepsin, papain or trypsase. Other than that, in acid method, acetic acid, citric acid or hydrochloric acid of $0.5 \mathrm{~mol} / \mathrm{L}$, with $\mathrm{pH} 2-3$ is being used.

In acid soluble collagen (ASC), the acid solvents that can be used in acid methods are acetic acid, citric acid 
and hydrochloric acid. The type and concentration of acid used will influence the swelling properties and solubilisation of collagen (Normah and Suryati, 2015; Hadfi and Sarbon, 2019). Then it leads to variations in molecular weight distribution and depends on the persistence of some of the cross-links between collagen chains (Giménez et al., 2005). However, studies of collagen extraction show that acetic acid is the most promising solvent in the extraction process of collagen (Kittiphattanabawon et al., 2010; Singh et al., 2011). Since acetic acid may destroy the salt bonds between molecules and Schiff bases and cause collagen fibers to expand and dissolve (Yang and Shu, 2014). In addition, acetic acid can cleave the hydrogen bonds, which initially can stabilise the triple-helical structures of collagen. The hydrolysis process also will occur faster in acid method (Yang and Shu, 2014).

However, in enzyme extraction, pepsin will be used as the extraction process (pepsin soluble collagen, PSC). This is because pepsin is a digestive protease, which can increase up the extraction yields of collagen. Since pepsin will breaks down the proteins into peptides (Zhao et al., 2011). However, this reaction can only act on nonhelix peptide chains, and it usually does not affect helix peptide chains. Therefore, this method will retain the triple helix section in collagen proteins, so the collagen is still in biologically active (Yang and Shu, 2014). In addition, the alkaline method is simple and easy to be controlled, but it usually uses in gelation production. Besides that, the enzyme method claims that the reactions occur in this method are mild and would not corrode the equipment used. Other than that, the enzyme method also consumes low energy compared to the other extraction method.

Selayang, Curut, Sardin or Basung are the local name of shortfin scad, are the low-value tropical fish that commonly found in Malaysia and normally it was used for salted fish, frozen and canned production (Sarbon et al., 2014). The shortfin scad is distributed mainly in the waters off Southern Japan and in the East China Sea (Shiraishi et al., 2010). The statistic of world capture Decapterus spp. in 2015, was about 1,411,567 tonnes (FAO, 2015). In addition, the statistics for the by-product of shortfin scad produce per daily from Maperow Sdn. Bhd., Kuala Terengganu is approximately in $1000 \mathrm{~kg}$ from the sample of fish weight in the range of 2500 to $3000 \mathrm{~kg}$. Therefore, the development of collagen from shortfin scad waste, give advantage since it gives a value -added to these underutilised fish species (Sarbon et al., 2014). Moreover, the cost to get the collagen resources was low compared to other marine animals. Other than collagen, shortfin scad also has been used in the extraction of gelatin by Cheow et al. (2007) in the previous study. Thus, the extraction of collagen from shortfin scad waste was believed to be successful which beneficial as an additional food ingredient.

\section{Materials and methods}

\subsection{Materials}

Waste of shortfin scad which is a mixture of bone and skin parts were obtained from the fish processing industry, Maperow Sdn. Bhd., Kuala Terengganu. Samples were brought to the laboratory in ice condition. Meanwhile, commercial collagens from tilapia skin were purchased from UMATY Industries Sdn. Bhd., Selangor. All other chemicals used were of analytical grade.

\subsection{Sample preparation}

Waste of shortfin scad which mixture of bone and skin parts was washed in excessive water and ground into coarse form by using a blender. Then, it was packed in a polyethylene bag and stored at $-20^{\circ} \mathrm{C}$ for further use.

\subsection{Collagen extraction}

\subsubsection{Pre-treatment of shortfin scad by-products}

Pre-treatment was conducted prior to the isolation process and characterisations were proceeds, to make sure all the unwanted materials were removed. Therefore, there were no unwanted materials that will affect the characteristics of the collagen produced. This also to make sure that the collagen was fully extracted without any foreign materials.

\subsubsection{Removal of non-collagenous proteins}

Treated samples were soaked and stirred in $0.1 \mathrm{M}$ sodium hydroxide $(\mathrm{NaOH})$ solution with ratio 1:8 (w/v) for $6 \mathrm{hrs}$. The $\mathrm{NaOH}$ solution was changed for every 3 hrs and then it was washed thoroughly with cold distilled water until the rinsed water become neutral $(\mathrm{pH} 7)$ as measured by using $\mathrm{pH}$ meter (Hukmi and Sarbon, 2018).

\subsubsection{Removal of minerals (Demineralising)}

Samples were soaked in 0.5 M ethylenediaminetetraacetic acid (EDTA) at $\mathrm{pH} 7.4$ for 24 hrs with continuous stirring. The solution was changed for every $12 \mathrm{hrs}$. Then, it was washed with distilled water for 3 times (Hamdan and Sarbon, 2019).

\subsection{Isolation of collagen}

\subsubsection{Extraction of acid soluble collagen (ASC)}

The samples were undergone acid soluble collagen (ASC) extraction by using $0.5 \mathrm{M}$ acetic acid with samples to solution ratio $1: 10(\mathrm{w} / \mathrm{v})$ for $24 \mathrm{hrs}$ with continuous stirring. The extracts were centrifuged at 10 , $000 \times g$ for $30 \mathrm{mins}$ at $4^{\circ} \mathrm{C}$ and the supernatant was 
separated. The residues then were re-extracted with 0.5 $\mathrm{M}$ acetic acid with samples to solution ratio of 1:10 (w/v) for $12 \mathrm{hrs}$ and undergo centrifugation (Gyrozen 150R, Korea) at $10,000 \times \mathrm{g}$ for $30 \mathrm{mins}$ at $4^{\circ} \mathrm{C}$. Both supernatants was combined and sodium chloride $(\mathrm{NaCl})$ was added to salt out until the final concentration of the supernatant was $0.7 \mathrm{M}$ for the precipitation to occur. The supernatant was centrifuged again at $2,500 \times \mathrm{x}$ to obtain the precipitate. The precipitate were then lyophilised (Baderi and Sarbon, 2019).

\subsubsection{Extraction of pepsin soluble collagen (PSC)}

In order to isolate pepsin soluble collagen (PSC), the un-dissolved matter which was from the acid soluble collagen (ASC) extraction was used, in order to provide a parallel comparison of these collagens (Hamdan and Sarbon, 2019). In addition, the remaining insoluble collagen can undergo further extraction, without damage the triple helix-structure by using strong alkali or enzymes (Nalinanon et al., 2008). The further extraction was using 2 volumes of $0.5 \mathrm{M}$ acetic acid which containing $1.5 \%(\mathrm{w} / \mathrm{w})$ pepsin for 30 hours at $4^{\circ} \mathrm{C}$ with continuous stirring. Then the extracts were centrifuged at $10,000 \times g$ for 30 mins at $4^{\circ} \mathrm{C}$ and the supernatant were separated. The residue was re-extracted with $0.5 \mathrm{M}$ acetic acid containing $1.5 \%(\mathrm{w} / \mathrm{w})$ pepsin for 12 hours before centrifuged at $10,000 \times \mathrm{g}$ for $30 \mathrm{mins}$ at $4^{\circ} \mathrm{C}$. Both supernatant were combined and sodium chloride $(\mathrm{NaCl})$ was added to salt out until the final concentration of the supernatant was $0.7 \mathrm{M}$ for the precipitation to occur. The supernatant was further centrifuged at 2,500 x $g$ to obtain precipitate. The precipitate were then lyophilised.

\subsection{Chemical composition}

The chemical compositions (moisture, crude protein, fat and ash content) of raw shortfin scad (Decapterus macrosoma) by-products and the extracted collagens were determined according to AOAC (2002) standard procedures. Analyses were carried out in triplicates and calculated on a dry weight basis of samples.

\subsection{Protein concentration}

The concentration of protein was determined by using Biuret's method, following Martina and Vojtech (2015) with a slight modification. Bovine serum albumin (BSA) was used as the protein standard to obtain the standard curve, to determine the concentration of protein in each collagen. Approximately $100 \mathrm{mg}$ of bovine serum albumin was dissolved into $10 \mathrm{~mL}$ of distilled water, to be used as the protein standard. The protein standard was pipetted with distilled water. Approximately $8.0 \mathrm{~mL}$ of biuret reagent was added and left for 30 mins at room temperature. By using a spectrophotometer (Cary 50, Varian, Inc., United States), the absorbance at $570 \mathrm{~nm}$ was measured. Then, collagen powder was diluted in distilled water with a ratio of 1:5, so the final concentration of protein can get into the range of the calibration curve that has been prepared.

\subsection{Structural properties}

Functional groups of extracted collagen were characterized by using Fourier Transform Infrared Spectroscopy (FTIR) following Hadfi and Sarbon, (2019) with a slight modification. The infrared spectra were set in the range from 4000 to $400 \mathrm{~cm}^{-1}$ using an infrared spectrophotometer (Nicolet, Thermo Electron, United States). The sample was prepared by added potassium bromide $(\mathrm{KBr})$ with a ratio of 1:100 and made it into the disc by using Auto fine coater (JFC 1600, Tokyo, Japan). From the peak produces at a certain wavelength and absorbance, the functional group and mode of its vibration were identified.

\subsection{Solubility}

The solubility of collagens was tested using different $\mathrm{pH}$ level according to the method from Ong et al. (2020) with some modification. Approximately $240 \mathrm{mg}$ of lyophilised collagens was dissolved in $80 \mathrm{~mL}$ of $0.5 \mathrm{M}$ acetic acid for $12 \mathrm{hrs}$ at $4^{\circ} \mathrm{C}$. About $8 \mathrm{~mL}$ of sample was transferred to a centrifuge tube and $\mathrm{pH}$ was adjusted in the range from 1 to 10 with $6 \mathrm{~N} \mathrm{NaOH}$ or $6 \mathrm{~N} \mathrm{HCl}$. The volume was made up to $10 \mathrm{~mL}$ with distilled water. The solution was stirred for $30 \mathrm{mins}$ at $4^{\circ} \mathrm{C}$ and then was centrifuged (Gyrozen 150R, Korea) at 10, $000 \times \mathrm{g}$ for 30 mins at $4^{\circ} \mathrm{C}$. About $2 \mathrm{~mL}$ of the sample was then transferred into the test tube with $8 \mathrm{~mL}$ of biuret reagent was added into the same test tube. Then the solubility was determined using a spectrophotometer (Cary 50, Varian, Inc., United States). The dissolved collagen which also the dissolved protein was determined as protein content in the supernatant by using biuret's method with bovine serum albumin as a protein standard. The concentration of protein content was determined by using the standard curve (Martina and Vojtech, 2015).

\subsection{Morphological structure}

The morphological analysis was referred to Saharuddin with a slight modification (Hamdan and Sarbon, 2018). The collagen powder was mounted on aluminium cylinder stubs $(5 \mathrm{~mm} \times 12.5 \mathrm{~mm})$ and sputtercoated with Auto fine coater (JFC 1600, Tokyo, Japan). The microstructure of the collagen was examined using a tabletop microscope (TM-1000) at a magnification of $\mathrm{x} 500$. 


\subsection{Statistical analysis}

All data collected were measured in triplicate and data were presented as mean \pm standard deviation. Analysis of Variance (ANOVA) was performed and means comparisons were done by Tukey's Test. The probability value of $p<0.05$ was considered significant. The analysis was performed by using Minitab Version 14, 2008.

\section{Results and discussion}

\subsection{Yield of extracted collagen}

The yield obtained for the extracted collagen from acid soluble collagen (ASC) and pepsin soluble collagen (PSC) was $3.35 \pm 3.43 \%$ and $0.10 \pm 0.13 \%$, respectively. Acetic acid was used in the acid method to produce ASC. As acetic acid can cleave the hydrogen bonds between molecules and Schiff bases and cause fibers to expanded and dissolved (Yang and Shu, 2014). This is because, collagen with the predominant monomeric molecule was solubilized in the presence of acid (Hickman et al., 2000). The yield of ASC was high compared to collagen extracted from bones of Bigeye snapper (Priacanthus tayenus) by Kittiphattanabawon et al. (2005). However, the yield of extracted collagen was low compared to the study from Singh et al. (2011), on the production of collagen from the skin of Striped catfish (Pangasianodon hypophthalmus). Meanwhile, pepsin used in pepsin extraction caused cross-linked molecules at the telopeptide region to cleaved, since the samples were digested by pepsin enzyme. However, the integrity of the triple helix was not damaged by this reaction (Veeruraj et al., 2013). This is because pepsin can only break down the proteins into peptides which it only acts on non-helix peptide chains (Misra, 2010). In addition, the yield of PSC was lower due to the prepared sample for pepsin extraction was taken from undissolved matter from acid soluble collagen extraction. The yield of PSC in this study corresponded with the finding from Jongjareonrak et al. (2005) on the production of collagen from the skin of Bigeye snapper (Priacanthus marcracanthus) with yield was about $1.1 \%$. Studies show that the different concentration and time used were considered to extract the collagen using pepsin enzyme. As these parameters were important in influencing the increasing value in yield of collagen extraction.

\subsection{Chemical composition}

The results obtained showed that the raw shortfin scad by-products contained high in moisture, followed by protein, ash and fat, which was $71.20 \pm 0.54 \%$, $23.19 \pm 2.58 \%, 16.24 \pm 0.69 \%, 2.49 \pm 0.24 \%$, respectively (Table 1). The results were in the same agreement with the finding by Kittiphattanabawon et al. (2010) for cartilage of Blacktip shark (Carcharhinus limbatus), where the moisture, protein, ash and fat content was $70.92 \pm 0.84 \%, \quad 14.85 \pm 0.02 \%, \quad 12.09 \pm 0.24 \% \quad$ and $0.21 \pm 0.02 \%$, respectively.

Meanwhile, the protein contents of ASC $(22.86 \pm 0.50 \%)$ and PSC $(26.97 \pm 1.02 \%)$, were significantly $(\mathrm{p}<0.05)$ lower than commercial collagen (93.68 $\pm 5.06 \%)$. The results for both extracted collagen of ASC and PSC corresponded with collagen from the skin of Brownbanded bamboo shark (Chiloscyllium punctatum) as a study by Kittiphattanabawon et al. (2010). However, according to Pavel et al. (2013), Kjeldahl method showed the lowest sensitivity for proteins due to indirect determination of proteins via nitrogen. Therefore, results from this finding are accurate but not precise (Pavel et al., 2013).

On the other hand, the fat content of ASC $(0.38 \pm 0.64 \%)$ was significantly higher than commercial collagen $(0.04 \pm 0.01 \%)$. The fat content of ASC corresponded with collagen from the skin of Brownbanded bamboo shark (Chiloscyllium punctatum) which is $0.4 \%$ by Kittiphattanabawon et al. (2010). The results also approved that the fat content from extracted collagen of ASC is higher than commercial collagen, due to the absence of the defatting process in the pretreatment steps. Conversely, the ash content in ASC $(60.90 \pm 0.53 \%)$ was significantly higher, compared to commercial collagen $(4.42 \pm 0.01 \%)$. The ash content in commercial collagen corresponded to the ash content on collagen from scales of Spotted golden goatfish (Parupeneus heptacanthus), as found by Matmaroh et al. (2011). On the other hand, ash in ASC could be removed effectively with $0.5 \mathrm{M}$ ethylenediaminetetraacetic acid (EDTA) with $\mathrm{pH}$ 7.4. However, in this analysis, it showed that no reduce in ash content was found from raw sample of shortfin scad by-products to collagen extracted of ASC after pre-treatment was done. This may due to incomplete washed of the sample with distilled water, which causes some of EDTA solution still had on the sample. Unfortunately, the sample cannot undergo complete demineralizing in the pre-treatment process.

\subsection{Protein concentration}

Results presented in Table 1 revealed that there was significant difference $(p<0.05)$ between commercial collagen, ASC and PSC, since the commercial collagen contained higher protein concentration compared to ASC and PSC, which were $4.21 \pm 0.26 \mathrm{mg} / \mathrm{mL}, 0.85 \pm 0.07 \mathrm{mg} /$ $\mathrm{mL}$ and $2.69 \pm 0.47 \mathrm{mg} / \mathrm{mL}$, respectively. The higher the protein concentration influenced by the higher of amino acids contents in the collagen. According to Veeruraj et al. (2013), glycine is a major amino acid presents in the 
Table 1. Chemical composition in raw material of shortfin scad by-products and extracted collagen as compared to commercial collagen

\begin{tabular}{cccccc}
\hline \multirow{2}{*}{ Samples } & \multicolumn{3}{c}{ Chemical composition (\%) } & Protein concentration \\
\cline { 2 - 5 } & Moisture & Protein & Fat & Ash & $(\mathrm{mg} / \mathrm{mL})$ \\
\hline Raw shortfin scad by-product & $71.20 \pm 0.54$ & $23.19 \pm 2.58$ & $2.49 \pm 0.24$ & $16.24 \pm 0.69$ & - \\
Commercial collagen & $10.11 \pm 0.13^{\mathrm{a}}$ & $93.68 \pm 5.06^{\mathrm{a}}$ & $0.04 \pm 0.01^{\mathrm{b}}$ & $4.42 \pm 0.01^{\mathrm{b}}$ & $4.21 \pm 0.26^{\mathrm{a}}$ \\
ASC & $5.23 \pm 0.28^{\mathrm{b}}$ & $22.86 \pm 0.50^{\mathrm{b}}$ & $0.38 \pm 0.64^{\mathrm{a}}$ & $60.90 \pm 0.53^{\mathrm{a}}$ & $0.85 \pm 0.07^{\mathrm{c}}$ \\
PSC & - & $26.97 \pm 1.02^{\mathrm{b}}$ & - & - & $2.69 \pm 0.47^{\mathrm{b}}$ \\
\hline
\end{tabular}

Values are expressed as means \pm standard deviation. Values with different superscript letter within the column are significantly different $(\mathrm{p}<0.05)$ between commercial collagen and extracted collagen. ASC: Acid Soluble Collagen, PSC: Pepsin Soluble Collagen.

collagen, which are critical for the formation of superhelical structures. In addition, one of the factors that affect the protein concentration is the amount of imino acid which are proline and hydroxyproline. Hydroxyproline plays an important role to stabilize the triple helix of collagen that will determine the potential use of collagen (Schrieber and Gareis., 2007). Then, pyrrolidine rings will maintain the superhelical structure by conformational restrictions, and the hydroxyl group of Hyp will further strengthen the structure by the interchain of hydrogen bonds (Nagai et al., 2008).

Results obtained showed that PSC contains higher protein concentration than ASC. This result was in agreement with finding on collagen extracted from the skin of Eel-fish (Evenchelys macrura) by Veeruraj et al. (2013) and Balloon fish (Diodon holocanthus) by Huang et al.(2011), as the imino acids contents in PSC was higher than ASC. In addition, the amino acids contents among animals were associated with different living environments of their sources, particularly habitat temperature (Singh et al., 2011). The benefit of using the Biuret method is, it is simple, inexpensive and provides a higher degree of selectivity for protein than total nitrogen -based methods (Moore et al., 2010).

\subsection{Functional groups}

Figure 1 shows the existence of amide A, II and III in ASC, PSC from shortfin scad by-products and commercial collagen from tilapia scales. The finding shows that amide A in ASC was higher compared to PSC, which was existed on wavelength of $3455.75 \mathrm{~cm}^{-1}$ and $3448.64 \mathrm{~cm}^{-1}$, respectively. However, commercial collagen shows the lowest wavelength in amide $\mathrm{A}$ compared to ASC and PSC which was $3423.22 \mathrm{~cm}^{-1}$. It commonly occurs in the range of $3400-3440 \mathrm{~cm}^{-1}$. However, amide A also could be in the range of 3318$3550 \mathrm{~cm}^{-1}$, since a study from Sujithra et al. (2013) for collagen from tilapia (Oreochromis niloticus) waste proved that the finding was in the same agreement. Amide A provided N-H stretching between molecules, which approves that collagen is one of the protein sources that contain a lot of hydrogen bond donors and acceptors (Hubbard and Haider, 2010). When N-H group of a peptide is involved in a hydrogen bond, the position starts to shift to lower frequencies (Zhao and Wang, 2015). Results proved that commercial collagen has a more stable structure compared to ASC and PSC due to repeating unit of alpha-helix and beta sheets that responsible for $\mathrm{N}-\mathrm{H}$ stretching. This study can be related to the result from protein concentration analysis. Since commercial collagen contents high in protein concentration than ASC and PSC, so the amide A of commercial collagen was low in wavelength due to hydrogen bond that involved in $\mathrm{N}-\mathrm{H}$ group of protein. Therefore, there was a significant difference $(p<0.05)$ between commercial collagen and extracted collagen of ASC and PSC.

While amide II was observed at $1589.86 \mathrm{~cm}^{-1}$ for ASC and at $1559.69 \mathrm{~cm}^{-1}$ for PSC. Amide II is the $\mathrm{CH}_{2}$

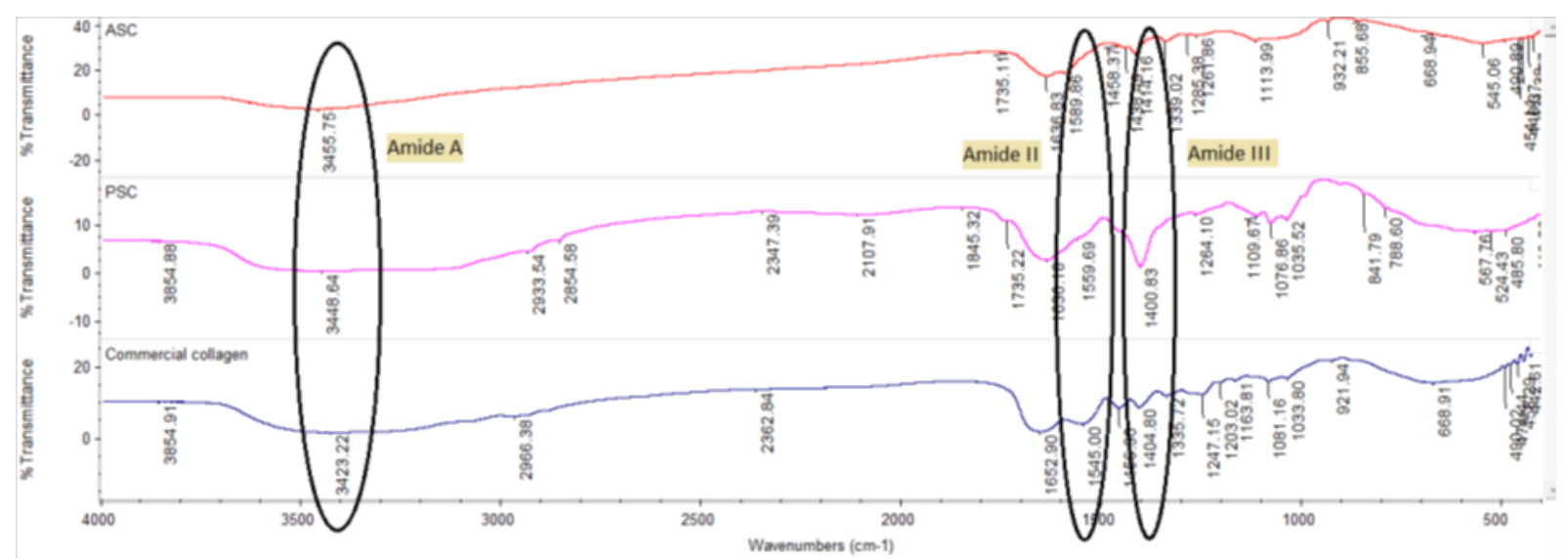

Figure 1. Functional groups in ASC, PSC and Commercial collagen 
bend, which the combination of N-H bending and C-N asymmetric stretching vibrations of group - $\mathrm{CO}-\mathrm{NH}-$ in the trans form (Sanden, 2011). This shows that the results obtained for amide II were in the same agreement with the finding by Duan et al. (2009), for collagen from skin, scale and bone of Carp (Cyprinus carpio) with the wavelength range of $1550 \mathrm{~cm}^{-1}-1600 \mathrm{~cm}^{-1}$. The wavenumber of amide II for ASC is higher than PSC, therefore ASC may have a valuable structural of collagen (Sanden, 2011). However, commercial collagen shows the lowest wavenumber when compared with both ASC and PSC, which was $1545.00 \mathrm{~cm}^{-1}$. In addition, results also show that there was a significant difference $(\mathrm{p}<0.05)$ between ASC, PSC and commercial collagen.

On the other hand, amide III in ASC and PSC were depicted at $1414.16 \mathrm{~cm}^{-1}$ and $1400.83 \mathrm{~cm}^{-1}$, respectively. The results were in similar agreement with finding from Plepis et al.(1996). As amide III is complex with intermolecular interactions that consist of components from $\mathrm{C}-\mathrm{N}$ stretching and $\mathrm{N}-\mathrm{H}$ in plane deformation, as well as absorption that arise from wagging vibrations from $\mathrm{CH}_{2}$ groups from the glycine backbone and proline side-chains (Bykov and Asher, 2010). However, PSC had a lower wavenumber, due to the removal of the telopeptide region during the extraction process (Matmaroh et al., 2011). Meanwhile, commercial collagen shows low wavenumber than ASC. Results show that there was a significant difference $(\mathrm{p}<0.05)$ between ASC and PSC with commercial collagen. In general, the structural obtained from FTIR analysis showed the extracted collagen possessed the fingerprint of collagen structure as in commercial collagen.

\subsection{Solubility}

The highest solubility of ASC, PSC and commercial collagen were at $\mathrm{pH} 1, \mathrm{pH} 2$ and $\mathrm{pH} 3$ respectively (Figure 2). Generally, collagens should be more soluble in acidic $\mathrm{pH}$, which is in the range of 1 to 4 and less soluble in isoelectric point (pI) (Wu et al., 2014). Since in the acid $\mathrm{pH}$, the charge will be positive which led to a strong electrostatic repulsion between collagen molecules. This cause in disrupting effects on the intrinsic stability of collagen molecules, which then prevent the droplets from aggregates and form coalescent. This study corresponded with finding from Veeruraj et al.(2013), which both ASC and PSC were exhibited higher solubilization in acidic $\mathrm{pH}$ from 1 to 4 .

The lowest solubilisation of collagen was in the alkaline range. As the lowest solubilisation point for ASC and PSC was at $\mathrm{pH} 8$ with $83.33 \pm 0.54$ and $24.76 \pm 32.21$. However, commercial collagen shows the lowest solubilisation point at $\mathrm{pH} 9$ which is $82.77 \pm 7.56$. The results of $\mathrm{pH}$ on protein solubility was related by isoelectric point (pI) value. $\mathrm{Wu}$ et al. (2014) reported that whenever the $\mathrm{pH}$ is lower or higher than the isoelectric point $(\mathrm{pI})$, the net charge residues of protein molecules are larger and thus the solubility is increased by the repulsion force between the chains. As according to Mezzenga and Fischer (2013), at the range of alkali condition, the electrostatic charge repulsion is decreased in the collagen molecules as the net charge tended to be zero, which cause in easier self-assembly. Therefore, the collagen molecules tend to be attracted to each other due to hydrophobic and Van der walls forces, which cause collagen molecules to aggregates and form coalescent. This finding was in the same agreement with the study by Singh et al. (2011), from the skin of striped catfish (Pangasianodon hypophthlmus), as collagen was found to have the lowest solubilisation point in the neutral and

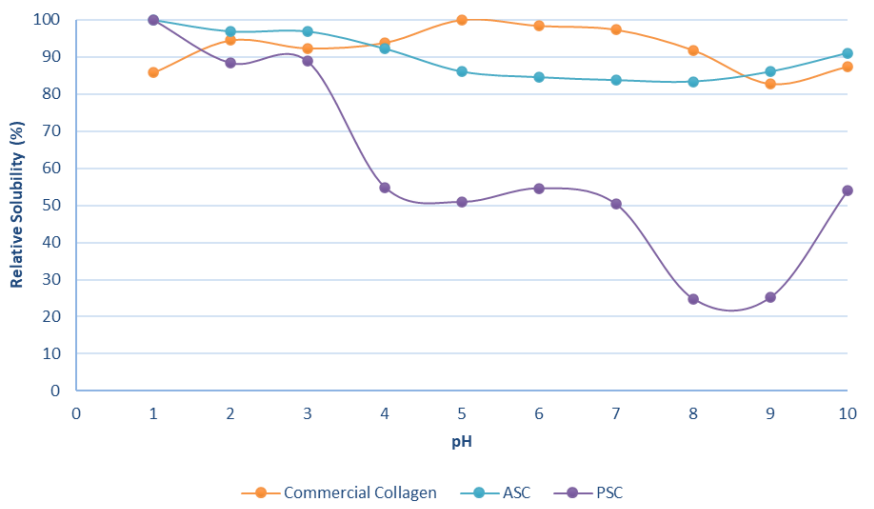

Figure 2. Solubility of ASC, PSC and commercial collagen in the $\mathrm{pH}$ range of 1 to 10

slightly alkaline $\mathrm{pH}$ range.

In addition, the results also show that ASC has high in solubility compared to PSC. Since PSC contain high in protein concentration that indicated high in amino acids, which will influence in stronger hydrophobic and Van der walls forces between collagen molecules and caused the formation of collagen coalescent. These showed that the solubilisation rate of PSC has a significant difference $(p<0.05)$ with ASC and commercial collagen (Figure 1). This indicated that the acid extraction method and enzyme extraction method could affect the solubility rate of collagen. According to Veeruraj et al.(2013), the solubility of ASC was high due to higher molecular weight protein than PSC.

\subsection{Morphological structure}

Extracted collagen of ASC and PSC from shortfin scad by-products with commercial collagen from tilapia scales are found as highly ordered 3D structure under Tabletop microscope (TM-1000) with high magnification (x500). As all the isolated collagens depicted different structures. However, both extracted collagen of ASC (Figure 3a) and PSC (Figure 3b) from 
shortfin scad by-products were in fibrils and porous structures. Besides that, there are agglomerated particles can be observed on the surface of both ASC and PSC. These unknown particles could be a sodium chloride compound that was used during the salt-out extraction process. The shape of sodium chloride is in crystal tabular form. The same unknown particles were also observed from the rat-tail tendon collagen under the microscope (Schuetz et al., 2013). They found that those free particles at the surface of the collagen scaffold

(a)

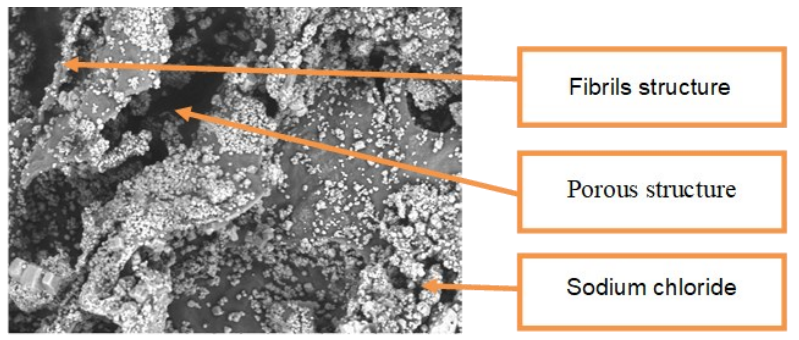

(b)

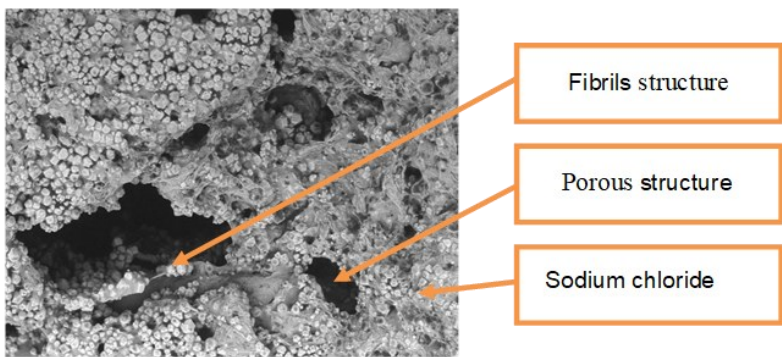

(c)

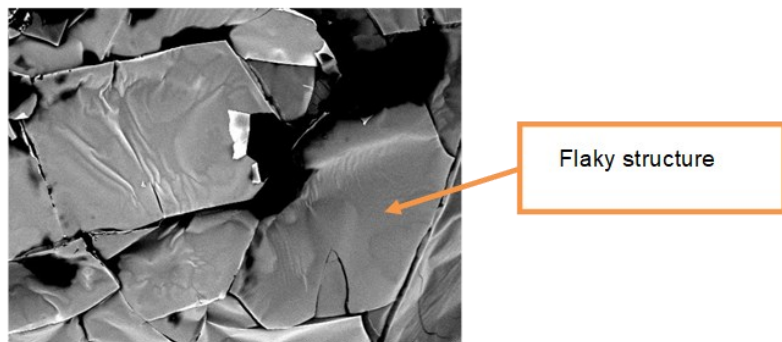

Figure 3. Morphological structures of (a) ASC, (b) PSC and (c) Commercial collagen

probably indicate minor damage to the collagen during the sample preparation process.

Meanwhile, the morphological structures for commercial collagen (Figure 3c) from tilapia scales show the form of a flaky structure. As those flaky structures occurred due to penetration of crystal into internal fibrillary plate overlap zone and cause the triplehelical structures of collagen to be compressed (Zhang, 2011). A similar structure was observed with finding from Wang et al. (2014) in the research of collagen from the muscle of amur sturgeon (Acipenser schrenckii), where a dense irregular sheet-like film that was linked by random-coiled filaments were observed. However, there were slight wrinkles on the surface of the collagen which are caused by the dehydration process during lyophilizing (Schuetz et al., 2013).

\section{Conclusion}

Acid soluble collagen (ASC) and pepsin soluble collagen (PSC) from shortfin scad waste were successfully isolated and characterized. This approved that acid method is more preferable to be used to extract collagen from fish waste since the extraction fraction of obtained collagen protein under acid method is much higher than the enzyme method. However, PSC shows better chemical composition than ASC, since it contains comparatively higher in protein and also in protein concentration than ASC. This study showed the new points on fish collagen in protein concentration. Meanwhile, FT-IR investigations showed the existence of spacial triple-helical structures of collagens that are important for collagen backbones, which also will influence the stable structure of collagen in ASC. Other than that, both ASC and PSC showed high solubility at acidic $\mathrm{pH}$ and have fibrils and porous structures with interconnectivity in the morphological analysis.

\section{References}

AOAC. (2002). Official Methods of Analysis, 17th ed. USA: Association of Official Analytical Chemists.

Baderi, N.A. and Sarbon, N.M. (2019). Microstructure, extractability and physicochemical properties of shortfin scad (Decapterus macrosoma) bone collagen as influenced by acetic acid concentration. International Food Research Journal, 26(2), 451 458.

Bond, O. (2014). Natural sources of collagen. Live strong.com. Retrieved on May 2, 2015 from livestrong website: http://www.livestrong.com/ article/342620-natural-sources-of-collagen/

Cheow, C.S., Norizah, M.S., Kyaw, Z.Y. and Howell, N.K. (2007). Preparation and characterisation of gelatins from the skins of sin croaker (Johnius dussumieri) and shortfin scad (Decapterus macrosoma). Food Chemistry, 101(1), 386-391. https://doi.org/10.1016/j.foodchem.2006.01.046

Duan, R., Zhang, J., Du, X., Yao, X. and Konno, K. (2009). Properties of collagen from skin, scale and bone of carp (Cyprinus carpio). Food Chemistry, 112(3), 702-706. https://doi.org/10.1016/ j.foodchem.2008.06.020

Giménez, B., Turnay, J., Lizarbe, M.A., Montero, P. and Gómez-Guillén, M.C. (2005). Use of lactic acid for extraction of fish skin gelatin. Food Hydrocolloids, 19(6), 941-950. https://doi.org/10.1016/ j.foodhyd.2004.09.011

Hadfi, N.H. and Sarbon, N.M. (2019). Physicochemical properties of silver catfish (Pangasius sp.) skin collagen as influenced by acetic acid concentration. 
Food Research, 3(6), 783 - 790. https:// doi.org/10.26656/fr.2017.3(6).130

Hamdan, F.S. and Sarbon, N.M. (2019). Isolation and characterization of collagen from Fringescale sardinella (Sardinella fimbriata) waste materials. International Food Research Journal, 26(1), 133 140.

Hickman, D., Sims, T. J., Miles, C.A., Bailey, A.J., De Mari, M. and Koopmans, M. (2000). Isinglass/ collagen: denaturation and functionality. Journal of Biotechnology, 79(3), 245-257. https:// doi.org/10.1016/S0168-1656(00)00241-8

Huang, Y.R., Shiau, C.Y., Chen, H.H. and Huang, B.C. (2011). Isolation and characterization of acid and pepsin-solubilized collagens from the skin of balloon fish (Diodon holocanthus). Food Hydrocolloids, 25 (6), 1507-1513. https://doi.org/10.1016/ j.foodhyd.2011.02.011

Hubbard, R.E. and Haider, M.K. (2010). Hydrogen bonds in proteins: role and strength. Retrieved from eLS website: https:// doi.org/10.1002/9780470015902.a0003011.pub2

Hukmi, N.M.M. and Sarbon, N.M. (2018). Isolation and characterization of acid soluble collagen (ASC) and pepsin soluble collagen (PSC) extracted from silver catfsh (Pangasius sp.) skin. International Food Research Journal, 25(5), 1785-1791.

Jongjareonrak, A., Benjakul, S., Visessanguan, W. and Tanaka, M. (2005). Isolation and characterisation of collagen from bigeye snapper (Priacanthus marcracanthus) skin. Journal of the Science of Food and Agriculture, 85(7), 1203-1210. https:// doi.org/10.1002/jsfa.2072

Kittiphattanabawon, P., Benjakul, S., Visessanguan, W. and Shahidi, F. (2010). Isolation and characterization of collagen from the cartilages of brownbanded bamboo shark (Chiloscyllium punctatum) and blacktip shark (Carcharhinus limbatus). Food Science and Technology, 43(5), 792-800. https:// doi.org/10.1016/j.lwt.2010.01.006

Kittiphattanabawon, P., Benjakul, S., Visessanguan, W., Nagai, T. and Tanaka, M. (2005). Characterisation of acid-soluble collagen from skin and bone of bigeye snapper (Priacanthus tayenus). Food Chemistry, 89 (3), 363-372. https://doi.org/10.1016/ j.foodchem.2004.02.042

Liu, Z., Oliveira, A.C.M. and Su, Y.C. (2010). Purification and characterization of pepsinsolubilised collagen from skin and connective tissue of giant red sea cucumber (Parastichopus californicus). Journal of Agricultural and Food Chemistry, 58(2), 1270-1274. https:// doi.org/10.1021/jf9032415

Mahboob, S. (2015). Isolation and characterization of collagen from fish waste material-skin, scales and fins of Catla catla and Cirrhinus mrigala. Journal of Food Science and Technology, 52(7), 4296-4305. https://doi.org/10.1007/s13197-014-1520-6

Martina, V. and Vojtech, K. (2015). A comparison of biuret, Lowry and Bradford methods for measuring the egg's proteins. MendelNet, 2015, 394-398.

Matmaroh, K., Benjakul, S., Prodpan, T., Encarnacion, A.B. and Kishimura, H. (2011). Characteristics of acid soluble collagen and pepsin soluble collagen from scale of spotted golden goatfish (Parupeneus heptacanthus). Food Chemistry, 129(3), 1179-1186. https://doi.org/10.1016/j.foodchem.2011.05.099

Mezzenga, R. and Fischer, P. (2013). The self-assembly, aggregation and phase transitions of food protein systems in one, two and three dimensions. Reports on Progress in Physics, 76(4), 046601. https:// doi.org/10.1088/0034-4885/76/4/046601

Misra, A. (Ed.) (2010). Challenges in delivery of therapeutic genomics and proteomics, p. 686. USA: Elsevier.

Moore, J.C., Devries, J.W., Lipp, M., Griffiths, J.C. and Abernethy, R. (2010). Total protein methods and their potential utility to reduce the risk of food protein adulteration. Food Science and Food Safety, 9(4), 330-357. https://doi.org/10.1111/j.15414337.2010.00114.x

Nagai, T., Suzuki, N. and Nagashima, T. (2008). Collagen from common minke whale (Balaenoptera acutorostrata) unesu. Food Chemistry, 111(2), 296301. https://doi.org/10.1016/j.foodchem.2008.03.087

Normah, I. and Nur-Hani Suryati, N.H.M.Z. (2015). Isolation of threadfin bream (Nemipterus japonicus) waste collagen using natural acid from calamansi (Citrofortunella microcarpa) juice. International Food Research Journal, 22(6), 2294-2301.

Ong, T.Y., Shaik, M.I., and Sarbon, N.M. (2020). Isolation and characterization of acid soluble collagen (ASC) and pepsin soluble collagen (PSC) extracted from sharpnose stingray (Dasyatis zugei) skin. Food Research. [Accepted].

Pavel, C.I., Marghitas, L.A., Bonta, V., Mihai, C.M. and Tomos, L.I. (2013). Determination of total protein content in royal jelly: a comparison of the kjeldahl, the Bradford and the lowry methods. Lucrari Stiintifice Universitatea de Stiinte Agricole si Medicina Veterinara, Seria Zootehnie, 59, 209-212.

Plepis, A.M.D.G., Goissis, G. and Das, G.D.K. (1996). Dielectric and pyroelectric characterization of anionic and native collagen. 
Polymer Engineering Science, 36(24), 2932-2938.

Sanden, K.W. (2011). Development of vibrational spectroscopic techniques for measuring qualityrelated parameters of connective tissue. Norway: Norwegian University of Life Science, MSc. Thesis.

Sarbon, N.M., Cheow, C.S., Kyaw, Z.W. and Howell, N.K. (2014). Effects of different types and concentration of salts on the rheological and thermal properties of sin croaker and shortfin scad skin gelatin. International Food Research Journal, 21(1), 317-324.

Schrieber, R. and Gareis, H. (Eds.) (2007). Gelatine handbook: theory and industrial practice., p. 347. United Kingdom: Wiley-VCH Verlag GmbH \& Co. [Online]. https://doi.org/10.1002/9783527610969

Schuetz, T., Richmond, N., Harmon, M.E., Schuetz, J., Castaneda, L. and Slowinska, K. (2013). The microstructure of collagen type I gel cross-linked with gold nanoparticles. Colloids Surface B: Biointerfaces, 101, 118-25. https://doi.org/10.1016/ j.colsurfb.2012.06.006

Shiraishi, T., Tanaka, H., Ohshimo, S., Ishida, H. and Morinaga, N. (2010). Age, growth and reproduction of two species of scad decapteus macrosoma and D. macarellus in the waters off southern Kyushu, Japan agricultural research quarterly. Japan Agricultural Research Quarterly, 4(2), 197-206. https:// doi.org/10.6090/jarq.44.197

Singh, P., Benjakul, S., Maqsood, S. and Kishimura, H. (2011). Isolation and characterisation of collagen extracted from the skin of striped catfish (Pangasianodon hypophthalmus). Food Chemistry, 124(1), 97-105. https://doi.org/10.1016/ j.foodchem.2010.05.111

Sujithra, S., Kiruthiga, N., Prabhu, M.J. and Kumeresan, R. (2013). Isolation and determination of type I collagen from tilapia (Oreochromis nicoticus) waste. International Journal of Engineering and Technology, 5(3), 2181-2185.

Veeruraj, A., Arumugam, M. and Balasubramanian, T. (2013). Isolation and characterization of thermostable collagen from the marine eel-fish (Evenchelys macrura). Process Biochemistry, 48 (10), 1592-1602. https://doi.org/10.1016/ j.procbio.2013.07.011

Veit, G., Kobbee, B., Keene, D.R., Paulsson, M., Koch, M. and Wagener, R. (2006). Collagen XXVIII, a novel von Willebrand factor A domain-containing protein with many imperfections in the collagenous domain. Journal of Biology Chemistry, 281, 34943504. https://doi.org/10.1074/jbc.M509333200

Wang, Z., Wang, L., Lin, S., Liang, Q., Shi, Z., Xu, J. and Ma, H. (2014). Isolation and Characterization of Collagen from the Muscle of Amur Sturgeon (Acipenser schrenckii), Biotechnology and Bioprocess Engineering, 19, 935-941. https:// doi.org/10.1007/s12257-013-0638-0

Wu, G.P., Wang, X.M., Lin, L.P., Chen, S.H. and Wu, Q.Q. (2014). Isolation and characterization of pepsin -solubilized collagen from the skin of black carp (Mylopharyngdon piceus). Advances in Bioscience and Biotechnology, 5, 642-650. https:// doi.org/10.4236/abb.2014.57076

Yang, H. and Shu, Z. (2014). The extraction of collagen protein from pigskin. Journal of Chemical and Pharmaceutical Research, 6(2), 683-687.

Zhang, F. (2011). Preparation and characterisation of collagen from freshwater fish scales. Food and Nutrition Sciences, 2(8), 818-823. https:// doi.org/10.4236/fns.2011.28112

Zhao, J. and Wang, J. (2015). Understanding the amideII vibrations in $\beta$-peptides. Journal of Physical Chemistry, 119, 14831-14839. https:// doi.org/10.1021/acs.jpcb.5b08070

Zhao, L., Budge, S.M., Ghaly, A.E., Brooks, M.S. and Dave, D. (2011). Extraction, purification and characterization of fish pepsin: a critical review. Journal of Food Process and Technology, 2(6), 1000126. https://doi.org/10.4172/21577110.1000126 